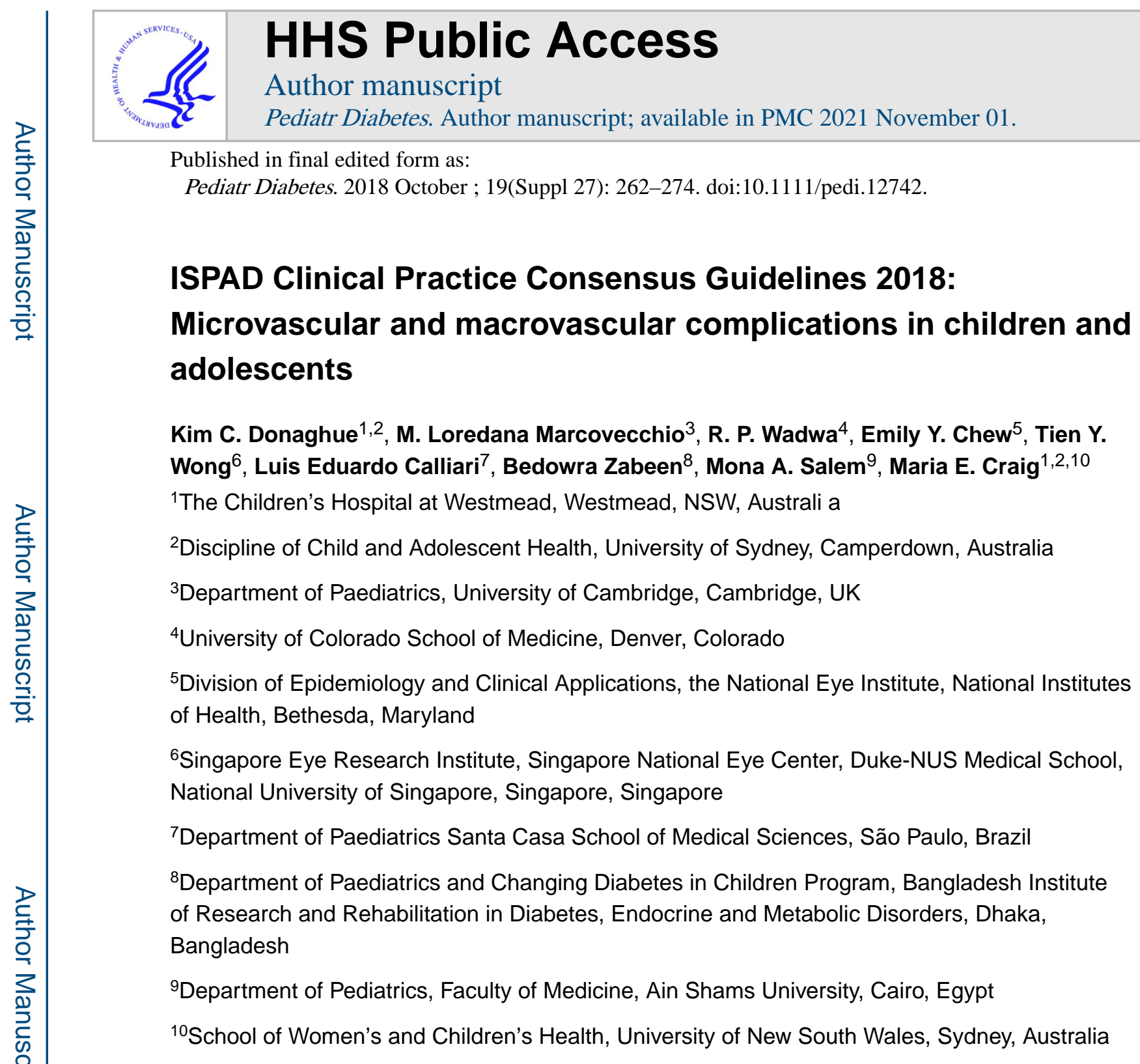

\title{
1| WHAT IS NEW?
}

\section{1| Recommendations}

1. Commence screening for microvascular complications at age 11 years (formerly 10 years)

2. Screening for microvascular disease should be performed preconception and during each trimester of pregnancy

3. Screen for lipid abnormalities in the non-fasting state

4. Screen for renal disease by first morning albumin creatinine ratio as the preferred method

Correspondence Prof. Kim Donaghue, The Children's Hospital at Westmead, Locked Bag 4001, Westmead, NSW 2145, Australia. kim.donaghue@health.nsw.gov.au.

Conflict of interest

The authors have declared no conflicts of interest. 


\subsection{Recommendations-Screening for and prevention of complications}

\subsubsection{Prevention}

- Intensive education and treatment should be used in children and adolescents to prevent or delay the onset and progression of vascular complications. A

- Achievement of target glycemic control will reduce the risk for onset and progression of diabetes vascular complications. A

- $\quad$ Screening should be performed preconception and each trimester of pregnancy. B

\subsubsection{Albuminuria}

- $\quad$ Screening for albuminuria should start from age 11 years with 2 to 5 years diabetes duration. $\mathbf{C}$

- Annual screening for albuminuria should be undertaken by first morning urine samples for urinary albumin/creatinine ratio (ACR). $\mathbf{E}$

- Because of biological variability, two of three urine samples should be used as evidence of albuminuria. Confounders are exercise, menstrual bleeding, infections, fever, kidney diseases, and marked hyperglycemia. Abnormal screening tests should be repeated, as albuminuria may be transient. $\mathbf{E}$

- $\quad$ Angiotensin converting enzyme inhibitors (ACEIs) or angiotensin receptor blockers (ARBs) agents should be used in adolescents with persistent albuminuria to prevent progression to proteinuria. $\mathbf{E}$

\subsection{3 | Retinopathy}

- $\quad$ Screening for diabetic retinopathy should start from age 11 years with 2 to 5 years diabetes duration. $\mathbf{B}$

- Screening for diabetic retinopathy should be performed by an ophthalmologist, optometrist, or a trained experienced observer through dilated pupils via biomicroscopy examination or fundal photography. B

- For those with diabetes duration less than 10 years, mild non-proliferative retinopathy (microaneurysms only) and good glycemic control, biennial screening assessment by biomicrocopic examination or fundal photography can occur. The frequency of retinopathy screening in general should occur biennially for these patients, but should be more frequent if there are high risk features for visual loss (Table 1). E

- Because of potential worsening of retinopathy for patients with longstanding poor glycemic control when control is rapidly improved, ophthalmological monitoring is recommended before initiation of intensive treatment and at three monthly intervals for 6 to 12 months thereafter, particularly if retinopathy is moderate non-proliferative stage or worse at the time of intensification. $\mathbf{E}$ 
- Laser treatment and intravitreal injections of anti-VEGF agents reduce the rate of visual loss for individuals with vision-threatening stages of retinopathy (severe non-proliferative retinopathy or worse and/or diabetic macular edema). A

\subsubsection{Other ocular conditions}

- A comprehensive initial eye examination should also be considered to detect cataracts, major refractive errors, or other ocular disorders. $\mathbf{E}$

\subsubsection{Neuropathy}

- $\quad$ Screening for peripheral neuropathy should start from age 11 years with 2 to 5 years diabetes duration and annually thereafter. $\mathbf{C}$

- Specific tests to evaluate diabetic neuropathy include assessment of sensation, vibration and reflexes in the feet for peripheral neuropathy, and orthostatic, heart rate variability for cardiac autonomic neuropathy. $\mathbf{E}$

\subsection{6 | Blood pressure}

- $\quad$ Blood pressure (BP) should be measured at least annually. E. Hypertension is defined as average systolic BP (SBP) and/or diastolic BP (DBP) that is 295 th percentile for gender, age, and height on three or more occasions $\mathbf{B}$.

- $\quad$ Confirmation of hypertension may be assisted by 24 hours ambulatory BP measurements. $\mathbf{E}$

- $\quad$ ACEI are recommended for use in children with diabetes and hypertension $\mathbf{E}$ (Table 2). They have been effective and safe in children in short-term studies $\mathbf{A}$, but are not safe during pregnancy. B

\subsection{7 | Lipids}

- $\quad$ Screening for dyslipidemia should be performed soon after diagnosis (when diabetes stabilized) in all children with type 1 diabetes from age 11 years $\mathbf{E}$. If normal results are obtained, this should be repeated every 5 years. If there is a family history of hypercholesterolemia, early cardiovascular disease (CVD) or if the family history is unknown, screening should commence as early as age 2 years $\mathbf{E}$.

- $\quad$ Screening with a fasting lipid profile is ideal but not always practical in youth with diabetes mellitus. Non-fasting lipids screening may be obtained and if triglycerides or Low density lipoprotein (LDL) levels are elevated, a fasting lipid profile would then be indicated. $\mathbf{E}$

- $\quad$ High LDL cholesterol is defined as $>2.6 \mathrm{mmol} / \mathrm{L}(100 \mathrm{mg} / \mathrm{dL})$ E. If this is present then interventions to improve metabolic control, dietary changes and increased exercise should be instituted.

- If the above interventions do not lower LDL cholesterol $<3.4 \mathrm{mmol} / \mathrm{L}$ (130 mg/ dL), statins should be commenced in children from age 11 years $\mathbf{E}$ (Table 2). 


\subsubsection{Lifestyle}

- $\quad$ Prevention or cessation of smoking will reduce progression of albuminuria and CVD B.

\subsubsection{Macrovascular disease}

- Screening of BP and lipids is recommended, as above. The benefit of routine screening for other markers of macrovascular complications outside the research setting is unclear $\mathbf{E}$.

\subsubsection{0 | Type 2 diabetes}

- Complications screening should commence at diagnosis. Attention to risk factors should be escalated because of the increased risk of complications and mortality B. (See also the ISPAD Guidelines chapter on type 2 Diabetes.)

\section{2 | INTRODUCTION}

The long-term vascular complications of diabetes include nephropathy, retinopathy, neuropathy, and macrovascular disease. The outcomes are:

- renal failure and hypertension due to diabetic nephropathy

- visual impairment and blindness due to diabetic retinopathy

- $\quad$ pain, paresthesia, muscle weakness due to peripheral neuropathy

- $\quad$ postural hypotension, gastroparesis, diarrhea, bladder paresis and impotence, due to autonomic neuropathy

- $\quad$ cardiac disease, peripheral vascular disease, and stroke due to macrovascular disease

Clinically evident diabetes-related vascular complications are rare in childhood and adolescence. However, early functional and structural abnormalities may be present a few years after the onset of the disease.

Childhood and adolescence is a period during which intensive education and treatment may prevent or delay the onset and progression of complications. ${ }^{1}$

There has been a declining incidence of complications reported in many areas with specialized clinics. ${ }^{2,3}$ This has occurred over a period of time during which there have been major changes and intensification of diabetes management, identification of putative risk factors, and the advent of regular screening for complications. There is no evidence that this is a worldwide occurrence: in areas where health care is not optimal, a greater risk of complications will remain. ${ }^{4}$ Nevertheless vascular complications still remain a key contributor to mortality in young people with an onset of diabetes during childhood. ${ }^{5}$

\subsection{Interventional studies of intensive glycemic control}

The diabetes control and complications trial (DCCT) was a multicenter, randomized controlled clinical trial involving 1441 patients with type 1 diabetes conducted in North 
America from 1983 to $1993^{6}$. Study participants included 195 pubertal adolescents (aged 13-17 years). Patients were randomized to either intensive or conventional treatment. The DCCT provided unequivocal evidence that intensive diabetes treatment and improved glycemic control conferred a significant risk reduction for microvascular complications compared with conventional treatment ${ }^{6}$.

After completion of the DCCT (a median in the whole group of 6.5 years) and hence the end of randomization, the Epidemiology of Diabetes Interventions and Complications (EDIC) study continued to follow patients. The EDIC study demonstrated that this positive effect continued after the end of the intervention: that is, that there was a memory effect of improved glycemic control, now called a legacy effect. ${ }^{7-9}$ During this phase a positive effect of the intensive therapy for reduction in macrovascular disease was also identified with a $50 \%$ reduction in cardiovascular events over 17 years. ${ }^{10,11}$

In the adolescent cohort, the intensive treatment compared with conventional treatment (for a median of 7.4 years), reduced the risk and progression of diabetic retinopathy by $53 \%$, clinical neuropathy by $60 \%$, and microalbuminuria by $54 \%$. The difference in HbA1c was $8.1 \%$ vs $9.8 \%$. The benefits of intensive therapy persisted in the former adolescent cohort for 4 years during the EDIC study: with a 74\% risk reduction for vision-threatening retinopathy, $48 \%$ less microalbuminuria, and $85 \%$ less albuminuria. ${ }^{9}$

\subsection{Other risk factors for the development of complications}

Longer duration of diabetes, older age, and puberty are risk factors for complications. A higher prevalence of microvascular complications has been reported for adolescent girls compared with boys. ${ }^{12,13}$ The prepubertal years of diabetes duration have a significantly lesser impact especially further from the onset of gonadarche ${ }^{14}$; however, the risk of vascular complications is greater for those living with diabetes during puberty, compared to young people who develop diabetes after puberty. ${ }^{15}$ For the same diabetes duration, age and puberty increase the risk for retinopathy and elevated albumin excretion rate (AER). ${ }^{16}$ Longitudinal studies have also reported that younger age of type 1 diabetes onset, particularly before puberty, is associated with a longer time free of complications such as nephropathy and retinopathy. ${ }^{14}$ However, in the long term this initial advantage disappears. $^{12}$

High rates of cardiovascular risk factors have been found in children and adolescents with type 1 diabetes from Norway and in SEARCH, a population-based study from the United States. ${ }^{17,18}$

Smoking is associated with an increased risk of developing persistent albuminuria. ${ }^{19}$ The evidence for the effect of smoking on retinopathy is less clear. Type 1 diabetes and smoking interact to produce excess cardiovascular morbidity and mortality. ${ }^{20}$

High blood pressure (BP) and alterations in the circadian BP rhythm have been associated with the risk of developing nephropathy and retinopathy in youth with type 1 diabetes. ${ }^{21-23}$ Hypertension has a greater impact on cardiovascular disease (CVD) in diabetic patients 
than in non-diabetic individuals. ${ }^{24} \mathrm{BP}$ control ( $<130 / 80 \mathrm{~mm} \mathrm{Hg}$ in adults) is effective in decreasing cardiovascular morbidity and mortality in diabetes. ${ }^{25}$

Dyslipidemia was associated with microalbuminuria and retinopathy development in the DCCT/EDIC and other studies. ${ }^{26-28}$ This included higher total LDL cholesterol and higher non-High density lipoprotein (HDL) cholesterol levels for microalbuminuria, as well as larger LDL particle size and apolipoprotein B in men.

Family history of vascular complications or cardiovascular risk factors increases the risk for nephropathy. ${ }^{29,30}$ Higher body mass index (BMI) is a risk factor for microalbuminuria, ${ }^{31}$ retinopathy ${ }^{32}$, neuropathy, ${ }^{33}$ and CVD. ${ }^{34}$

Lifestyle issues also contribute to complications risk; sedentary men with diabetes have higher mortality than active individuals. ${ }^{35}$

Celiac disease is also an independent risk factor for retinopathy, early elevation of AER nephropathy in patients with type 1 diabetes. ${ }^{36,37}$

\subsection{Diabetic nephropathy}

Diabetic nephropathy is a major cause of morbidity and mortality amongst young adults with type 1 diabetes. In the absence of diabetic nephropathy, mortality in patients with type 1 diabetes is similar to that in the general population, whereas it is significantly higher in patients with abnormal urinary AER. ${ }^{38,39}$

The changes occurring in the kidney in patients with type 1 diabetes are generally classified into five stages, reflecting specific and progressive alterations in renal morphology and function. The earliest stage is characterized by glomerular hypertrophy, hyperfiltration, and hyperperfusion. This is followed by a stage of subclinical morphological changes and increases in albumin excretion rates (AER) within the normal range. ${ }^{40}$ Further increases in albumin excretion, with an AER between 30 and $300 \mathrm{mg} / 24 \mathrm{~h}$ or 20 and $200 \mu \mathrm{g} / \mathrm{min}$ in a 24-hour or timed urine collection, indicate the development of albuminuria (formerly "microalbuminuria") (stage 3), which may further progress to overt proteinuria (formerly termed "macroalbuminuria)" (AER > $200 \mu \mathrm{g} / \mathrm{min}$ or $>300 \mathrm{mg} / 24 \mathrm{~h}$ ) (stage 4) and, without any treatment, to end-stage renal disease (ESRD) (stage 5). ${ }^{41}$

Although advanced stages of nephropathy, such as overt proteinura or ESRD, are rare in children and adolescents with type 1 diabetes, early structural and functional renal alterations develop soon after diagnosis of diabetes, and often progress during puberty. Biopsy studies have shown that renal lesions, such as basement membrane thickening and mesangial expansion, can be detected in young normoalbuminuric subjects and these changes are predictive of subsequent albuminuria. ${ }^{42}$

Albuminuria with AER $<200 \mu \mathrm{g} / \mathrm{min}$ has been for long time considered as the earliest clinical manifestation of nephropathy and a key risk factor for progression to proteinuria. However, $40 \%$ to $50 \%$ of cases of albuminuria can be transient or intermittent and thus not necessarily progress toward more advanced stages of nephropathy. However, as highlighted 
by recent studies, even if albuminuria regresses into the normal range, patients' experiences intermittent microalbuminuria have an increased cardiorenal risk. ${ }^{12,43}$

Extensive evidence indicates that increases in albumin excretion, even within the normal range, predict CVD risk in adults with type 1 diabetes as well as in non-diabetic populations. ${ }^{44}$ In young people with childhood-onset type 1 diabetes, early increases in albumin excretion rates can occur during the first years after diagnosis and can predict future risk of albuminuria and proteinuria. ${ }^{45} \mathrm{In}$ an incident cohort, after 6 years duration, early elevation of AER ( $>7.5 \mu \mathrm{g} / \mathrm{min}$ ) was examined as an even earlier marker of renal dysfunction. Comparing children before and after 11 years, elevated AER was present in 5\% compared to $25 \%$; and comparing children before and after puberty, it was present in 5\% compared to 26\% ${ }^{16}$ There has been no secular reduction in AER or albuminuria in the same cohort that has shown a reduction in retinopathy: $24 \%$ to $22 \%$ in the short duration cohort $(2-<5 \text { years duration })^{46} ; 45 \%$ to $30 \%$ in the cohorts with median duration 8.6 years. ${ }^{3}$ Similar results have been found in Bangladesh. ${ }^{47}$ The recent results from the screening phase of the adolescent type 1 diabetes cardiorenal intervention trial (AdDIT) showed that adolescents aged 10 to 16 years, with increased urinary albumin excretion levels (upper tertile of the normal range) had higher glomerular filtration rate (GFR) and increased CVD risk, as indicated by higher lipid levels, arterial stiffness, increased aortic intima media thickness, and signs of impaired cardiac autonomic function. ${ }^{48-50}$

2.3.1 | Screening for albuminuria-One of the first markers of diabetic nephropathy is albuminuria, ${ }^{51}$ which is defined as any of those below:

- Albumin/creatinine ratio (ACR) 2.5 to $25 \mathrm{mg} / \mathrm{mmol}$ or 30 to $300 \mathrm{mg} / \mathrm{g}$ (spot urine) in males and 3.5 to $25 \mathrm{mg} / \mathrm{mmol}$ or 42 to $300 \mathrm{mg} / \mathrm{g}$ in females (because of lower creatinine excretion)

Values above the upper limit of the albuminuria range denote proteinuria.

Assessing ACR in a spot urinary sample is the easiest method to carry out in an office setting and it generally provides accurate information. First-voided urine in the morning is preferable because of the known diurnal variation in albumin excretion and postural effects. A random sample can be used but being aware that this is associated with an increased risk of false positive results, and therefore in case of an abnormal result, screening should be repeated with first morning urine collections. Timed overnight or 24 hour collections are more burdensome and add little to prediction or accuracy. ${ }^{52,53}$

Confounding factors to be considered when screening for albuminuria are: strenuous exercise, infections, kidney disease (ie, IgA or other types of nephritis), marked hyperglycemia, fever, menstrual bleeding. All these factors can lead to increased ACR/AER.

Albuminuria is confirmed by finding 2 or all of three samples abnormal over a 3- to 6-month period. Persistent albuminuria has been shown to predict the progression to end stage renal failure ${ }^{51,54}$ and is associated with an increased risk of macrovascular disease. ${ }^{44}$

Regular follow-up is important to identify rapid or slow progression to albuminuria, as well as cases of regression to normoalbuminuria. Regular longitudinal follow-up of albumin 
excretion is also important to identify patients with progressive small increases of urinary albumin excretion within the normal range, which might be a prelude to the development of albuminuria.

\subsection{Antihypertensive treatment for prevention of nephropathy}

Effective antihypertensive therapy in patients with nephropathy prolongs the time to endstage renal disease. ${ }^{55,56} \mathrm{~A}$ recent prospective study has shown further improvement in prognosis with preservation of renal function in those diagnosed with nephropathy after 2000, associated with better control of BP, greater use of Renin angiotensin system (RAS) inhibition, better control of lipids and glycemia control and less smoking. ${ }^{57}$ Hypertension in children is defined as BP equal to or above the 95th percentile for age, sex, and height, whereas in adolescents (age $\geq 13$ years) it is defined as SBP $\geq 130$ and/or diastolic BP (DBP) $\searrow 80 \mathrm{~mm} \mathrm{Hg}$.

Elevated BP (previously known as "prehypertension") is defined as BP $\geq 90$ th percentile for age, sex, and height, or from the age of 13 years as BP between 120 and 129/80 mm Hg. Similar to overt hypertension, elevated BP is associated with adult hypertension and potentially amenable to treatment. 58,59

Children and adolescents found to have elevated BP or hypertension should have elevated BP confirmed on three separate days. Confirmation of hypertension may be assisted by 24 hours ambulatory BP measurements (ABPM). Normative ABPM values are available and should be used for the interpretation of the results. ${ }^{60}$

In children and adolescents with elevated BP, initial treatment includes lifestyle interventions, including DASH diet and moderate to vigorous physical activity at least 3 to 5 days per week (30-60 minutes per session). ${ }^{58,61,62}$ If target BP is not reached within 3 to 6 months of initiating lifestyle intervention, pharmacologic treatment should be considered.

When hypertension is confirmed in children and adolescents with type 1 diabetes, in addition to lifestyle modification, pharmacologic treatment of hypertension should be considered. ${ }^{63}$ Pharmacologic treatment of hypertension in children and adolescents should be initiated with an angiotensin converting enzyme inhibitor (ACEI), angiotensin receptor blocker (ARB), long-acting calcium channel blocker, or a thiazide diuretic. Angiotensin converting enzyme inhibitors (ACEI) are recommended for use in children and adolescents with hypertension and albuminuria but an angiotensin receptor blocker can be used if the ACE inhibitor is not tolerated (eg, due to cough). ${ }^{63}$ They have been effective and safe in children in short-term studies. ${ }^{64-66}$

Reproductive counseling and implementation of effective birth control is required when treatment is implemented, due to the potential teratogenic effects of both drug classes. The goal of treatment is BP consistently <90th percentile for age, sex, and height.

In adults, ACEI and angiotensin II receptor blockers (ARBs) reduce progression from microalbuminuria to macroalbuminuria and increase the regression rate to normoalbuminuria. ${ }^{67,68} \mathrm{~A}$ systematic review and meta-analysis showed that in subjects with diabetes, only ACEI can prevent the doubling of serum creatinine compared to placebo. ${ }^{69}$ 
In addition, in placebo-controlled studies, only ACEI (at the maximum tolerable dose) significantly reduced the risk of all-cause mortality. ${ }^{70}$

A recent meta-analysis including trials comparing RAS blockers vs other antihypertensive agents in people with diabetes (and largely without albuminuria or proteinuria) did not show any superior effect of RAS blocker for the prevention of renal and cardiovascular outcomes, and suggest that any class of antihypertensive agents can be used in people with diabetes especially in those without renal impairment. ${ }^{71}$

Despite the above evidence mainly in adults, there are still some concerns regarding the use of ACEI in protecting long-term renal function in young people without hypertension. In meta-analysis of individual patient data, the beneficial effects were more modest in those with the lowest levels of microalbuminuria. ${ }^{72}$ Young people with albuminuria would potentially be taking ACEI for decades. Side effects include cough, hyperkalemia, headache, and impotence ${ }^{73,74}$. A key safety issue related to the use of ACEI, as well as to ARBs, is the potential risk of congenital malformation when used during pregnancy. A recent systematic review has highlighted that fetal exposure to ACEI or ARBs has serious neonatal and long-term complications and recommend to improve the awareness of these potential deleterious effects. ${ }^{75}$ Therefore, when starting treatment with these drugs in adolescent girls, they need to be aware of this risk and birth control measure need to be recommended.

Recent data from AdDIT, where 443 adolescents were randomized to treatment with an ACE inhibitor (Quinapril, $5 \mathrm{mg}$ ), a statin (Atorvastatin, $10 \mathrm{mg}$ ), a combination of both or placebo using a two-by-two factorial design, indicate that treatment with ACE inhibitors over 2 to 4 years in adolescents with type 1 diabetes deemed to be at risk of complication based on their ACR in the upper tertile of the normal range is safe, with only few reported side effects, mainly hypotension (requiring drug reduction). Treatment with ACE inhibitors in this group did not have any significant effect on the primary outcome measure (change in area under the curve of $\log _{10} \mathrm{ACR}$ ), but was associated with a $43 \%$ decrease in the secondary outcome cumulative incidence of microalbuminuria during the 2 to 4 year treatment period, although that did not reach statistical significance. ${ }^{66}$

\section{5 | Diabetic retinopathy}

Non-proliferative retinopathy is characterized by microaneurysms, retinal hemorrhages both pre- and intraretinal, cotton wool spots related to ischemia and microinfarction, hard exudates due to protein and lipid leakage, intraretinal microvascular abnormalities (IRMAs), and venular dilatation and tortuosity. Mild and moderate stages of non-proliferative retinopathy are not vision-threatening and do not invariably progress to more severe stages of retinopathy. ${ }^{76}$

Severe non-proliferative retinopathy (previously known as preproliferative) is characterized by vascular obstruction, increase in number of retinal hemorrhages and microaneurysms, IRMAs, marked venous abnormalities, and ischemia and infarctions of the retinal nerve fibers causing cotton wool spots. 
Proliferative diabetic retinopathy (PDR) is characterized by neovascularisation in the retina and/or vitreous posterior surface. The vessels may rupture or bleed into the vitreoretinal space which is vision-threatening and/or.

Diabetic macular edema/maculopathy is characterized by decreased vascular competence and microaneurysm formation which produce exudation and swelling in the central retina.

Adolescents have a higher risk of progression to vision threatening stages of retinopathy (severe non-proliferative retinopathy or worse and/or diabetic macular edema) compared to adults with diabetes. ${ }^{77}$ The progression may be rapid, especially in those with poor glycemic control. ${ }^{78}$ Hence, adolescence is the time when efforts should be directed to screening for early signs of diabetic retinopathy and modifiable risk factors. Regression of retinopathy can also occur with improved glycemic control. ${ }^{79,80}$ Regular screening for diabetic retinopathy has reduced the proportion of blind patients due to diabetes. ${ }^{81,82}$

In the United Kingdom, a national screening program was introduced from 2002 with the initial age of screening starting at 12 years because there were no reports of visionthreatening retinopathy before this age. ${ }^{83}$ Recently, reported results of 2125 adolescents screened at age 12 to 13 years found referral retinopathy rates of less than $20 \%$, but of these, three individuals with short duration $(<5$ years) required fast track referral for moderate to severe retinopathy. At subsequent 5-year follow-up, progression to vision-threatening retinopathy had occurred in $9 \%$ of adolescents diagnosed before age 5 years and in 3\% diagnosed at age 5 to 7 years.

Recent reports have found low rates of referral for retinopathy screening in well-controlled diabetes pediatric clinics. ${ }^{84,85}$ In the T1D Exchange Registry in the United States, less than $1 \%$ of 12235 patients reported treatment for retinopathy ${ }^{86}$ at a mean age of 12 years and duration 5 years, although this is likely to under-report the actual prevalence since the data were based self-reported retinopathy and only cases requiring treatment.

Conversely, insurance claims data show markedly higher rates reported by optometrists or ophthalmologists in a large US managed-care network: $20 \%$ of 2240 youth had developed diabetic retinopathy at a median duration of 3.2 years with an incident rate of 52.3 per 1000 person-years; estimated to be $25 \%$ at 5 years duration. Severe retinopathy or macular oedema was present in $2 \%$ and the youngest patient with PDR was age 6 years. Lower rates of screening uptake were found in those with lower family income and this group had higher rates of retinopathy, suggesting that the actual rate may be even higher. ${ }^{87,88}$

Initial worsening of diabetic retinopathy can occur with the initiation of improvement in glycemic control as occurred in the DCCT but such worsening did not result in clinically significant visual loss and over time, intensive therapy continued to be superior to standard therapy. This initial worsening of diabetic retinopathy with improvement of glycemic control also occurred in patients with growth failure due to severe under-insulinization. ${ }^{89,90}$ However, within 1.5 to 3 years, the advantage of intensive treatment is evident. ${ }^{89}$ Pregnancy is a recognized risk for acceleration and progression of retinopathy ${ }^{91,92}$; hence, screening for retinopathy should be undertaken preconception, every trimester and 1 year postpartum. 
2.5.1 Assessment of retinopathy-The most sensitive detection methods for retinopathy screening are a clinical bio-microscopic fundus slit examination through dilated pupils by an ophthalmologist or optometrist and mydriatic seven-field stereoscopic retinal photography. The latter is optimal for research but not often available in the clinical setting. Other methods are mydriatic and non-mydriatic two-field fundal photography, direct ophthalmoscopy, indirect ophthalmoscopy, fundus fluorescein angiography, and optical coherence tomography (OCT). Fundal photography provides a validated result that can be useful for monitoring clinical quality and in research, but photographs may be not be gradable in which case ophthalmoscopy needs to be performed; mydriasis can reduce the technical failure rate. ${ }^{93}$ Fluorescein angiography reveals functional vascular abnormalities (vascular permeability) as well as structural abnormalities in the blood vessels whereas OCT reveals only structural abnormalities, specifically macular oedema and other structural abnormalities including loss of the various layers of the neural retina.

The landmark study of diabetic retinopathy carried out in Wisconsin starting in 1980 to 1982, examined prevalence of retinopathy using seven-field stereoscopic retinal photography in people diagnosed with diabetes less than 30 years of age and on insulin within 1 year of diagnosis. ${ }^{94}$ With longer diabetes duration there was an increase in retinopathy, so that after 15 years $98 \%$ had background retinopathy and after 35 years duration $62 \%$ had proliferative retinopathy. This study helped establish the existence of screening for diabetic retinopathy and the search and treatment of risk factors. Subsequent changes in diabetes management have been associated with a reduction in proliferative retinopathy demonstrated by comparison with a later diagnosed study group. After 20 years diabetes duration the later onset group of type 1 patients examined in 2007 to 2011, had less proliferative retinopathy than the earlier onset group examined 1980 to $1996: 18 \%$ vs $43 \% .80$

When an incident cohort of children was examined for retinopathy after 6 years duration, the relative effects of age and puberty could be compared. Seven-field stereoscopic fundal photography was performed with early retinopathy defined as one microaneurysm or hemorrhage, which was present in $24 \%$. Comparing children before and after 11 years, retinopathy was present in $8 \%$ vs $25 \%$; and comparing children before and after puberty, it was present in $12 \%$ vs $29 \%$. The incident cohort was diagnosed in 1990 to 1992 and examined in 1996 to 1998 when their median HbA1c was $8.7 \%{ }^{16}$

More recent data using the same methods in mid-adolescence (median age 16.4 years) with median diabetes duration of 8.6 years demonstrated that retinopathy declined from 53\% (in 1990-1994) to $23 \%$ (in 2000-2004) and then to $12 \%$ (in 2005-2009). ${ }^{3}$ In a younger group aged 11 to 17 years (median age 14.5 years, duration 2-5 years), the prevalence of mild background retinopathy declined from $16 \%$ in 1990 to 1994 to $7 \%$ in 2003 to $2006 .{ }^{46}$ Furthermore, those with shorter duration had considerably less retinopathy, and retinopathy was present in only 6\% of the youngest group (aged 11-13 years) over the whole time of observation.

2.5.2 Specific treatment for retinopathy-Once sight-threatening retinopathy has been detected, treatment options include laser photocoagulation and/or anti-VEGF therapy. ${ }^{76,95}$ Panretinal laser photocoagulation (PRP), commonly known as "laser therapy," 
consists of multiple discrete outer retinal burns throughout the mid and far peripheral area but sparing the central macula. It has been proven to reduce the progression of visual loss by more than $50 \%$ in patients with PDR..$^{96,97}$ However, photocoagulation is not indicated for eyes with mild or moderate non-proliferative retinopathy. ${ }^{98}$ Side effects of treatment are decreased night and peripheral vision and subtle changes in color perception. Complications of laser therapy are vitreous and choroidal hemorrhages or visual sequelae of misplaced burns.

For PDR, intravitreal injection of anti-VEGF (ranibizumab, aflibercept, bevacizumab) is now increasingly used and show better 12-month results for visual acuity than PRP. ${ }^{99}$ This treatment is not destructive but does require repeated visits and injections for efficacy (eg, monthly injections for the first 5 months with up to nine injections in the first year); and carries the rare risk of ocular infection. ${ }^{100}$

For diabetic macular edema involving vision loss, anti-VEGF (ranibizumab, aflibercept, bevacizumab) is now considered standard of care and has shown superior outcomes over 5 years compared to laser treatment. ${ }^{101,102}$ Intravitreal use of steroids (dexamethasone and fluocinolone) was tested in phase 3 trials and approved by the Food and Drugs Administration (FDA) in the United States. However, because of the inferior visual acuity results and the potential adverse effects of cataract and glaucoma development, intravitreal steroid is rarely used as first-line of therapy for diabetic macular edema.

Surgical treatment such as vitrectomy may be indicated for persistent vitreous hemorrhage, tractional retinal detachment, or extensive fibrosis. ${ }^{95}$

\subsection{Diabetic cataracts}

Cataracts have been reported in type 1 diabetes close to or even preceding the diagnosis. ${ }^{85,103,104} \mathrm{~A}$ recent review found the prevalence to be $0.7 \%$ to $3.4 \%$ from 16 studies published since 1993. ${ }^{105}$ Hence, comprehensive initial eye examination should also be considered to detect cataracts, especially if there is any visual disturbance. Examination for cataracts should be performed otherwise at time of screening for diabetic retinopathy. Surgical removal may be required ( 49 of the reported 66 cases). ${ }^{105}$

\section{7| Diabetic neuropathy}

Diabetes can affect the somatic and autonomic nervous system. In youth, prevalence rates of peripheral neuropathy vary from $<10 \%$ to as high as $27 \%,{ }^{3,106,107}$ and may be increasing, ${ }^{108}$ although some of this variability may relate to different methods of screening in addition to recognized risk factors. Clinical symptoms of autonomic neuropathy are uncommon in the pediatric population, however, subclinical findings have been reported. ${ }^{109,110}$ The most important associations of diabetic neuropathy are with glycemic control ${ }^{111}$ and diabetes duration. ${ }^{112-114}$

2.7.1 Generalized neuropathy-The most common type of all diabetic neuropathies is the Diabetic Sensorimotor Polyneuropathy. The generic terms "diabetic neuropathy" and "peripheral neuropathy" are commonly used referring to this type of neuropathy. It is a polyneuropathy caused by a diffuse damage to all peripheral nerve fibers, motor, sensory, 
and autonomic. Such damage occurs insidiously and progressively and is characterized at first by sensory loss and later by mild loss of motor function, in a "stocking and glove" distribution. Small fiber dysfunction precedes large-fiber damage in diabetic sensorimotor polyneuropathy. ${ }^{115}$ Patients usually complain of numbness, prickling, burning and/or paresthesia of hands and/or feet, which can progress to persistent pain. ${ }^{113}$

2.7.2 Assessment of peripheral neuropathy-Physical examination should include clinical tests to evaluate: small-fiber function: temperature or pinprick sensation; large-fiber function: perception of vibration and soft touch sensation (usually $10 \mathrm{~g}$ monofilaments), and evaluation of ankle and knee tendon reflexes. ${ }^{113,116}$

Peripheral nerve lab tests include: quantitative vibration, thermal discrimination thresholds, and nerve conduction. These are mostly used in research settings or for more severe cases. Age- and gender-specific normal ranges need to be applied when interpreting results.

Focal neuropathies are less common and include mononeuropathies such as carpal tunnel syndrome, palsy of the peroneal nerve, palsy of the third cranial nerve, and proximal nerve conditions (eg, diabetic amyotrophy). Symptoms and diagnostic evaluation are related to the affected nerve.

2.7.3 Autonomic neuropathy-Autonomic neuropathy can affect many systems - the cardiovascular (CV), urogenital (UG) and gastro-intestinal (GI). Generally, the damage occurs gradually and progressively. While overt autonomic neuropathy is rare in childhood and adolescence, subclinical signs of autonomic dysfunction are common, and can be found even soon after diabetes diagnosis and may be accelerated by puberty. ${ }^{110}$ Symptoms and investigation are related to the affected system.

Autonomic neuropathy can cause postural hypotension, vomiting, diarrhea, bladder paresis, impotence, sweating abnormalities, impaired light reflex, impotence, and retrograde ejaculation. Abnormal heart rate responses and prolonged beginning of $Q$ wave to end of $\mathrm{T}$ wave on the electrocardiogram (QT) intervals have been associated with increased risk of sudden death. ${ }^{117}$ Risk factors for autonomic neuropathy in young people include longer diabetes duration, poor glycemic control, higher BMI, ${ }^{118}$ and presence of aldose reductase gene (AKR1B1) polymorphisms, specifically the Z-2/Z-2 genotype. ${ }^{119}$

Cardiovascular autonomic neuropathy (CAN): the most common cardiac symptom is postural hypotension and alteration of heart rate. Progression of loss of heart rate (HR) variability may increase risk of severe hypoglycemia, as it is associated with impaired awareness of hypoglycemia. ${ }^{120}$

Cardiac autonomic nerve tests include: heart rate response to deep breathing, standing from a lying position, Valsalva Maneuver, heart rate variation at rest, QT interval and postural changes in BP. ${ }^{110}$ Studies with young adults showed that resting heart rate, presence of somatic diabetic neuropathy, and retinopathy were independent factors associated with cardiac autonomic neuropathy. ${ }^{121}$ Abnormal heart rate responses and prolonged QT intervals have been associated with increased risk of sudden death. ${ }^{117}$

Pediatr Diabetes. Author manuscript; available in PMC 2021 November 01. 
Gastrointestinal: GI symptoms include those related to "diabetic gastroparesis" (retarded gastric emptying, nausea, postprandial vomiting, eructation), as well as those caused by lower intestinal compromise (abdominal pain, diarrhea, and fecal incontinence). ${ }^{122}$

Urogenital system: UG manifestations are usually related to bladder paresis (hesitation, increase in interval time between urination, inadequate emptying of bladder and urinary retention) and, more rarely, in adolescent males, erectile dysfunction. ${ }^{123}$

Other symptoms of AN include sweating abnormalities, generally presented as a reduction of sweating in a "stocking and glove" manner, that can progress to global anhydrosis, and alterations of pupillary adaptation response to light and dark. ${ }^{110}$

Clinical symptoms of autonomic neuropathy are uncommon in the pediatric population. However, subclinical findings have been reported including significant cardiac autonomic neuropathy detected with heart rate variability studies in youth with type 1 diabetes. ${ }^{109}$

\section{8| Macrovascular disease}

The mortality and morbidity of CVD are markedly increased in individuals with diabetes compared to the general population. ${ }^{124}$

Hypertension has a greater impact on CVD in patients with diabetes than in individuals without this condition. ${ }^{24} \mathrm{BP}$ control $(<140 / 80 \mathrm{~mm} \mathrm{Hg}$ in adults) reduces cardiovascular morbidity and mortality in diabetes. ${ }^{125}$

A family history of early CVD (before 55 years of age), lipid disturbances, type 2 diabetes, hypertension ${ }^{26,126,127}$ and smoking place the individual with diabetes at higher risk.

Atherosclerosis starts in childhood and adolescence as shown by intima-media thickness of the carotids and aorta ${ }^{128-130}$ and silent coronary atherosclerosis measured by intravascular ultrasound in young adults with childhood onset diabetes. ${ }^{131}$ Silent coronary atherosclerosis and cardiovascular events are strongly associated with poor glycemic control. ${ }^{131,132}$

Cholesterol plays an important role in the initiation and progression of atherosclerosis. Wellcontrolled type 1 diabetes is not associated with gross blood lipid disturbances, but more advanced lipoprotein subclass examinations reveal atherogenic profiles. ${ }^{28}$ Poor glycemic control was associated with a potentially more atherogenic lipoprotein profile. ${ }^{133}$

Changes in lipids associated with increased cardiovascular risk are also associated with central obesity in type 1 diabetes (as well as type 2 diabetes). ${ }^{134}$ Individuals with type 1 diabetes are at risk for hypercholesterolemia; the prevalence approached $50 \%$ of young adults in one study ${ }^{135}$. The prevalence of elevated non-HDL cholesterol was $25 \%$ in a study of individuals less than 21 years of age with type 1 diabetes. ${ }^{136}$

Adolescents with type 1 diabetes have higher levels of apolipoprotein B (apoB) compared to similar age non-diabetics. ${ }^{137}$ Studies in adults and adolescents with type 1 diabetes suggest a possible complementary role for measurement of apoB in addition to screening LDL-c. 
However, data are insufficient at this time to warrant the addition of apoB screening to current lipid screening guidelines for youth with diabetes.

In a cohort of adolescents with type 1 diabetes, those achieving 4 to 6 of the goals of Screening Guidelines had better surrogate markers of macrovascular disease than those achieving less, and have comparable results to non-diabetic controls. ${ }^{138}$

2.8.1 Management of dyslipidemia-In adults with diabetes, statins are effective in the primary and secondary prevention of major cardiovascular events including vascular mortality, stroke and limb and coronary revascularization. ${ }^{139,140}$ The Heart Protection Study was a 5 year interventional study of 5963 patients with diabetes, $10 \%$ of whom had type 1 diabetes. This benefit was independent of glycemic control and cholesterol levels. ${ }^{140}$

Short-term trials have shown that simvastatin, lovastatin, and pravastatin are effective and safe in children and adolescents, mainly in the context of familial hypercholesterolemia. ${ }^{141-143}$ No significant side effects were observed in terms of growth, pubertal Tanner grading, testicular volume, menarche, endocrine function parameters, or liver or muscle enzymes. ${ }^{143,144}$ The AdDIT trial confirmed the safety of statin (atorvastatin) in adolescents with type 1 diabetes treated for a 2 to 4 year period. ${ }^{66}$

High LDL cholesterol is defined as $>2.6 \mathrm{mmol} / \mathrm{L}(100 \mathrm{mg} / \mathrm{dL}) .{ }^{145}$ If this is present then interventions to improve metabolic control, dietary changes and increased exercise should be instituted. If the above interventions do not lower LDL cholesterol to $<3.4 \mathrm{mmol} / \mathrm{L} / 130$ $\mathrm{mg} / \mathrm{dL}$, statins should be considered in children aged $>10$ years, with an ideal target $<2.6$ $\mathrm{mmol} / \mathrm{L}(100 \mathrm{mg} / \mathrm{dL})$.

Lipids screening with a fasting lipid profile is not required. Data from the NHANES III study suggest that non-fasting lipids screening has good prognostic value ${ }^{146}$ but data in pediatric patients with diabetes are lacking. If triglycerides or LDL levels are elevated, a fasting lipid profile is then indicated. ${ }^{147}$ Fasting lipids are also indicated for patients under treatment for dyslipidemia.

\subsubsection{Functional changes in cardiac and peripheral vascular function-}

Diabetes is also associated with changes in cardiac and peripheral vascular function. In adults diabetes is associated with increased cardiovascular risk and altered cardiovascular function independent of hypertension or other coronary artery disease. ${ }^{148}$ Diastolic dysfunction is characterized by reduced early diastolic relaxation, changes ventricular filling patterns, ${ }^{149,150}$ increases in left ventricular filling pressure during exercise, ${ }^{151}$ and decreases resting and exercising end-diastolic volume (EDV). ${ }^{152}$ At a more advanced stage, these changes are collectively defined as diabetic cardiomyopathy, which may be a precursor to diastolic heart failure. ${ }^{153}$ Abnormalities in diastolic filling will affect stroke volume and thus cardiac output.

Previous studies in diabetic adults have shown that aerobic capacity and left ventricular stroke volume during exercise are associated with diastolic dysfunction in adults. ${ }^{152,154}$ Adults with asymptomatic type 1 diabetes have reduced exercise capacity and lower stroke volume at peak exercise compared with non-diabetic peers, limitations that are strongly 
associated with diastolic dysfunction ${ }^{154,155}$ and reduced EDV during exercise. ${ }^{152,154}$ Current evidence suggests that healthy adolescents with diabetes may also have lower aerobic capacity 156,157 and lower exercise stroke volume. ${ }^{156}$ In a recent study, 52 adolescents with type 1 diabetic (mean duration of diabetes was 6 years) were assessed at rest and during submaximal exercise (at a fixed heart rate) by cardiac magnetic resonance imaging (MRI). ${ }^{158}$ These data confirmed that not only was there reduced diastolic filling at rest but this was exacerbated with exercise reducing stroke volume further. Moreover, peak heart rate (the only other mechanism to increase cardiac output) was lower in adolescents with diabetes suggesting they will have impaired cardiac output which may limit their aerobic capacity. Diastolic filling was associated with HbA1c but not diabetes duration suggesting this could be reversed with improved control. Indeed, there are data from adult elite athletes with diabetes; those with better control have better cardiovascular performance compared to those with poorer control.

Similar to adults, peripheral vascular function is also impaired in children and adolescents with type 1 diabetes. Endothelial dysfunction is an early event in the development of atherosclerosis and it occurs early in type 1 diabetes. ${ }^{159,160}$ It appears to be intimately involved in the pathogenesis of microvascular and macrovascular complications of diabetes. ${ }^{160,161}$ Studies looking at flow mediated vasodilatation and glyceryl trinitrate have elegantly demonstrated impaired vasodilatation in children and adolescents. ${ }^{162-165}$ Associations with both hyperglycemia and hypoglycemia and reduced endothelial function have been made as well as an improvement of endothelial function with folate. ${ }^{163,166,167}$ However, folate supplementation was only successful when folate was deficient, with no effect of folate on vascular function in folate replete children. ${ }^{168}$ Increased physical activity may also be beneficial although this data remains conflicting. Impaired vasodilation of muscle capillary beds also results in increased systolic and diastolic BP during exercise. This has been demonstrated in maximal and submaximal exercise paradigms. ${ }^{158}$

Prevention of the later vascular complications of diabetes would be assisted by the identification of early abnormalities such as those observed in the heart and peripheral vasculature. While better glycemic control has been associated with better cardiac and peripheral vascular function other strategies improving of these early changes will potentially reduce the risk of later microvascular and macrovascular complications.

\section{9 | Type 2 and complications}

Type 2 diabetes in youth is associated with greater risk for microalbuminuria and hypertension than type 1 diabetes. ${ }^{47,107,108}$ Neuropathy may also be increased. ${ }^{107,169}$ Mortality data of those diagnosed at age 15 to 30 years suggest that mortality is higher in type 2 diabetes than type 1 diabetes, for the same level of glycemic control. ${ }^{169}$ Hence, complications screening and attention to risk factors should be more aggressive for youth with type 2 diabetes. In comparison to older people diagnosed with type 2 diabetes youth with this condition have greater risk of proliferative retinopathy for the same degree of glycemic control. ${ }^{170}$

Pediatr Diabetes. Author manuscript; available in PMC 2021 November 01. 


\section{3 | CONCLUSIONS}

Complications become less common when diabetes management is optimized. Other modifying factors are BP, weight, smoking and lipids, which are more significant/important in type 2 diabetes and insulin resistance. Screening for complications is important during adolescence and also to prepare for lifelong screening.

\section{REFERENCES}

1. Effect of intensive diabetes treatment on the development and progression of long-term complications in adolescents with insulin-dependent diabetes mellitus: diabetes control and complications trial. Diabetes Control and Complications Trial Research Group. J Pediatr. 1994;125:177-188. [PubMed: 8040759]

2. Bojestig M, Arnqvist HJ, Hermansson G, Karlberg BE, Ludvigsson J. Declining incidence of nephropathy in insulin-dependent diabetes mellitus. N Engl J Med. 1994;330:15-18. [PubMed: 8259139]

3. Downie E, Craig ME, Hing S, Cusumano J, Chan AKF, Donaghue KC. Continued reduction in the prevalence of retinopathy in adolescents with type 1 diabetes: role of insulin therapy and glycemic control. Diabetes Care. 2011;34:2368-2373. [PubMed: 22025782]

4. Majaliwa ES, Munubhi E, Ramaiya K, et al. Survey on acute and chronic complications in children and adolescents with type 1 diabetes at Muhimbili National Hospital in Dar es Salaam, Tanzania. Diabetes Care. 2007;30:2187-2192. [PubMed: 17563337]

5. Sandahl K, Nielsen LB, Svensson J, et al. Increased mortality in a Danish cohort of young people with type 1 diabetes mellitus followed for 24 years. Diabet Med. 2017;34:380-386. [PubMed: 27027777]

6. The effect of intensive treatment of diabetes on the development and progression of long-term complications in insulin-dependent diabetes mellitus. The Diabetes Contro 1 and Complications Trial Research Group. N Engl J Med. 1993;329:977-986. [PubMed: 8366922]

7. Diabetes Control and Complications Trial/Epidemiology of Diabetes Interventions and Complications Research Group, Lachin JM, Genuth S, Cleary P, Davis MD, Nathan DM. Retinopathy and nephropathy in patients with type 1 diabetes four years after a trial of intensive therapy. N Engl J Med. 2000;342:381-389. [PubMed: 10666428]

8. Writing Team for the Diabetes Control and Complications Trial/Epidemiology of Diabetes Interventions and Complications Research Group. Sustained effect of intensive treatment of type 1 diabetes mellitus on development and progression of diabetic nephropathy: the Epidemiology of Diabetes Interventions and Complications (EDIC) study. JAMA. 2003;290:2159-2167. [PubMed: 14570951]

9. White NH, Sun W, Cleary PA, et al. Effect of prior intensive therapy in type 1 diabetes on 10-year progression of retinopathy in the DCCT/EDIC: comparison of adults and adolescents. Diabetes. 2010; 59:1244-1253. [PubMed: 20150283]

10. Nathan DM, Cleary PA, Backlund J-YC, et al. Intensive diabetes treatment and cardiovascular disease in patients with type 1 diabetes. N Engl J Med. 2005;353:2643-2653. [PubMed: 16371630]

11. Intensive Diabetes Treatment and Cardiovascular Outcomes in Type 1 Diabetes: The DCCT/EDIC Study 30-Year Follow-up. Diabetes Care. 2016;39(5):686-693. [PubMed: 26861924]

12. Amin R, Widmer B, Prevost AT, et al. Risk of microalbuminuria and progression to macroalbuminuria in a cohort with childhood onset type 1 diabetes: prospective observational study. BMJ. 2008;336: 697-701. [PubMed: 18349042]

13. Benitez-Aguirre P, Craig ME, Cass HG, et al. Sex differences in retinal microvasculature through puberty in type 1 diabetes: are girls at greater risk of diabetic microvascular complications? Invest Ophthalmol Vis Sci. 2015;56:571-577. 
14. Donaghue KC, Fairchild JM, Craig ME, et al. Do all prepubertal years of diabetes duration contribute equally to diabetes complications? Diabetes Care. 2003;26:1224-1229. [PubMed: 12663601]

15. Cho YH, Craig ME, Donaghue KC. Puberty as an accelerator for diabetes complications. Pediatr Diabetes. 2014;15:18-26.

16. Donaghue KC, Craig ME, Chan AKF, et al. Prevalence of diabetes complications 6 years after diagnosis in an incident cohort of childhood diabetes. Diabet Med. 2005;22:711-718. [PubMed: 15910621]

17. Margeirsdottir HD, Larsen JR, Brunborg C, Overby NC, Dahl-Jorgensen K, Norwegian Study Group for Childhood Diabetes. High prevalence of cardiovascular risk factors in children and adolescents with type 1 diabetes: a population-based study. Diabetologia. 2008;51:554-561. [PubMed: 18196217]

18. Wood JR, Miller KM, Maahs DM, et al. Most youth with type 1 diabetes in the T1D exchange clinic registry do not meet American Diabetes Association or International Society for Pediatric and Adolescent Diabetes clinical guidelines. Diabetes Care. 2013;36:2035-2037. [PubMed: 23340893]

19. Shah AS, Dabelea D, Talton JW, et al. Smoking and arterial stiffness in youth with type 1 diabetes: the SEARCH Cardiovascular Disease Study. J Pediatr. 2014;165:110-116. [PubMed: 24681182]

20. Gay EC, Cai Y, Gale SM, et al. Smokers with IDDM experience excess morbidity. The Colorado IDDM Registry. Diabetes Care. 1992;15: 947-952. [PubMed: 1505327]

21. Lurbe E, Redon J, Kesani A, et al. Increase in nocturnal blood pressure and progression to microalbuminuria in type 1 diabetes. N Engl J Med. 2002;347:797-805. [PubMed: 12226150]

22. Marcovecchio ML, Dalton RN, Schwarze CP, et al. Ambulatory blood pressure measurements are related to albumin excretion and are predictive for risk of microalbuminuria in young people with type 1 diabetes. Diabetologia. 2009;52:1173-1181. [PubMed: 19305965]

23. Gallego PH, Craig ME, Hing S, Donaghue KC. Role of blood pressure in development of early retinopathy in adolescents with type 1 diabetes: prospective cohort study. BMJ. 2008;337:a918a918. [PubMed: 18728082]

24. Stamler J, Vaccaro O, Neaton JD, Wentworth D, The Multiple Risk Factor Intervention Trial Research Group. Diabetes, other risk factors, and 12-yr cardiovascular mortality for men screened in the multiple risk factor intervention trial. Diabetes Care. 1993;16:434-444. [PubMed: 8432214]

25. Hansson L, Zanchetti A, Carruthers SG, et al. Effects of intensive blood-pressure lowering and low-dose aspirin in patients with hypertension: principal results of the hypertension optimal treatment (HOT) randomised trial. HOT Study Group. Lancet. 1998;351:1755-1762. [PubMed: 9635947]

26. Loredana Marcovecchio M, Neil Dalton R, Toby Prevost A, et al. Prevalence of abnormal lipid profiles and the relationship with the development of microalbuminuria in adolescents with type 1 diabetes. Diabetes Care. 2009;32:658-663. [PubMed: 19171721]

27. Raile K, Galler A, Hofer S, et al. Diabetic nephropathy in 27,805 children, adolescents, and adults with type 1 diabetes: effect of diabetes duration, A1C, hypertension, dyslipidemia, diabetes onset, and sex. Diabetes Care. 2007;30:2523-2528. [PubMed: 17630266]

28. Jenkins AJ, Lyons TJ, Zheng D, et al. Lipoproteins in the DCCT/EDIC cohort: associations with diabetic nephropathy. Kidney Int. 2003;64: 817-828. [PubMed: 12911531]

29. Seaquist ER, Goetz FC, Rich S, Barbosa J. Familial clustering of diabetic kidney disease. Evidence for genetic susceptibility to diabetic nephropathy. N Engl J Med. 1989;320:1161-1165. [PubMed: 2710189]

30. Marcovecchio ML, de Giorgis T, Di Giovanni I, Chiavaroli V, Chiarelli F, Mohn A. Association between markers of endothelial dysfunction and early signs of renal dysfunction in pediatric obesity and type 1 diabetes. Pediatr Diabetes. 2016;18:283-289. [PubMed: 27246625]

31. Stone ML. Natural history and risk factors for microalbuminuria in adolescents with type 1 diabetes: a longitudinal study. Diabetes Care. 2006;29:2072-2077. [PubMed: 16936155]

32. Dorchy H, Claes C, Verougstraete C. Risk factors of developing proliferative retinopathy in type 1 diabetic patients: role of BMI. Diabetes Care. 2002;25:798-799. [PubMed: 11919142] 
33. De Block CEM, De Leeuw IH, Van Gaal LF. Impact of overweight on chronic microvascular complications in type 1 diabetic patients. Diabetes Care. 2005;28:1649-1655. [PubMed: 15983315]

34. Koivisto VA, Stevens LK, Mattock M, et al. Cardiovascular disease and its risk factors in IDDM in Europe. EURODIAB IDDM Complications Study Group. Diabetes Care. 1996;19:689-697. [PubMed: 8799621]

35. Moy CS, Songer TJ, LaPorte RE, et al. Insulin-dependent diabetes mellitus, physical activity, and death. Am J Epidemiol. 1993;137: 74-81. [PubMed: 8434575]

36. Pham-Short A C Donaghue K, Ambler G, et al. Early elevation of albumin excretion rate is associated with poor gluten-free diet adherence in young people with coeliac disease and diabetes. Diabet Med. 2013;31:208-212. [PubMed: 24117620]

37. Rohrer TR, Wolf J, Liptay S, et al. Microvascular complications in childhood-onset type 1 diabetes and celiac disease: a multicenter longitudinal analysis of 56,514 patients from the German-Austrian DPV database. Diabetes Care. 2015;38:801-807. [PubMed: 25690004]

38. Orchard TJ, Secrest AM, Miller RG, Costacou T. In the absence of renal disease, 20 year mortality risk in type 1 diabetes is comparable to that of the general population: a report from the Pittsburgh epidemiology of diabetes complications study. Diabetologia. 2010;53: 2312-2319. [PubMed: 20665208]

39. Groop P-H, Thomas MC, Moran JL, et al. The presence and severity of chronic kidney disease predicts all-cause mortality in type 1 diabetes. Diabetes. 2009;58:1651-1658. [PubMed: 19401416]

40. Mogensen CE, Christensen CK, Vittinghus E. The stages in diabetic renal disease. With emphasis on the stage of incipient diabetic nephropathy. Diabetes. 1983;32(suppl 2):64-78. [PubMed: 6400670]

41. Mogensen CE, Keane WF, Bennett PH, et al. Prevention of diabetic renal disease with special reference to microalbuminuria. Lancet. 1995;346:1080-1084. [PubMed: 7564792]

42. Steinke JM, Sinaiko AR, Kramer MS, et al. The early natural history of nephropathy in type 1 diabetes: III. Predictors of 5-year urinary albumin excretion rate patterns in initially normoalbuminuric patients. Diabetes. 2005;54:2164-2171. [PubMed: 15983218]

43. de Boer IH, Gao X, Cleary PA, et al. Albuminuria changes and cardiovascular and renal outcomes in type 1 diabetes: the DCCT/EDIC study. Clin J Am Soc Nephrol. 2016;11:1969-1977. [PubMed: 27797889]

44. Associations of kidney disease measures with mortality and end-stage renal disease in individuals with and without diabetes: a meta-analysis. Lancet. 2012;380:1662-1673. [PubMed: 23013602]

45. Schultz CJ, Neil HA, Dalton RN, Dunger DB, Oxforn Regional Prospective Study Group. Risk of nephropathy can be detected before the onset of microalbuminuria during the early years after diagnosis of type 1 diabetes. Diabetes Care. 2000;23:1811-1815. [PubMed: 11128358]

46. Cho YH, Craig ME, Hing S, et al. Microvascular complications assessment in adolescents with 2- to 5-yr duration of type 1 diabetes from 1990 to 2006. Pediatr Diabetes. 2011;12:682-689. [PubMed: 21435138]

47. Zabeen B, Nahar J, Islam N, Azad K, Donaghue K. Risk factors associated with microalbuminuria in children and adolescents with diabetes in Bangladesh. Indian J Endocrinol Metab. 2018;22:8588. [PubMed: 29535943]

48. Marcovecchio ML, Jones T, Daneman D, et al. Adolescent type 1 diabetes cardio-renal intervention trial (AdDIT): urinary screening and baseline biochemical and cardiovascular assessments. Diabetes Care. 2014;37:805-813. [PubMed: 24198300]

49. Maftei O, Peña AS, Sullivan T, et al. Early atherosclerosis relates to urinary albumin excretion and cardiovascular risk factors in adolescents with type 1 diabetes: Adolescent type 1 Diabetes cardiorenal Intervention Trial (AdDIT). Diabetes Care. 2014;37: 3069-3075. [PubMed: 25071076]

50. Cho YH, Craig ME, Davis EA, et al. Cardiac autonomic dysfunction is associated with high-risk albumin-to-creatinine ratio in young adolescents with type 1 diabetes in AdDIT (adolescent type 1 diabetes cardio-renal interventional trial). Diabetes Care. 2015;38:676-681. [PubMed: 25573882]

51. Mogensen CE. Microalbuminuria predicts clinical proteinuria and early mortality in maturity-onset diabetes. N Engl J Med. 1984;310 : 356-360. [PubMed: 6690964] 
52. American Diabetes Association. 10. Microvascular Complications and Foot Care: Standards of Medical Care in Diabetes-2018. Diabetes Care. 2017;41:S105-S118.

53. Lambers Heerspink HJ, Gansevoort RT, Brenner BM, et al. Comparison of different measures of urinary protein excretion for prediction of renal events. J Am Soc Nephrol. 2010;21: 1355-1360. [PubMed: 20634296]

54. Viberti G. Etiology and prognostic significance of albuminuria in diabetes. Diabetes Care. 1988;11:840-845. [PubMed: 3073075]

55. Bakris GL, Williams M, Dworkin L, Elliott WJ, Epstein M, Toto R. et al. , Preserving renal function in adults with hypertension and diabetes: a consensus approach. National Kidney Foundation Hypertension and Diabetes Executive Committees Working Group. Am J Kidney Dis. 2000;36:646-661. [PubMed: 10977801]

56. Parving HH, Andersen AR, Smidt UM, Homm el E, Mathiesen ER, Svendsen PA. Effect of antihypertensive treatment on kidney function in diabetic nephropathy. Br Med J (Clin Res Ed). 1987;294: 1443-1447.

57. Andrésdóttir G, Jensen ML, Carstensen B, et al. Improved prognosis of diabetic nephropathy in type 1 diabetes. Kidney Int. 2015;87: 417-426. [PubMed: 24918158]

58. Theodore RF, Broadbent J, Nagin D, et al. Childhood to early-midlife systolic blood pressure trajectories: early-life predictors, effect modifiers, and adult cardiovascular outcomes. Hypertension. 2015;66: 1108-1115. [PubMed: 26558818]

59. Chen X, Wang Y. Tracking of blood pressure from childhood to adult-hood: a systematic review and meta-regression analysis. Circulation. 2008;117:3171-3180. [PubMed: 18559702]

60. Soergel M, Kirschstein M, Busch C, et al. Oscillometric twenty-four-hour ambulatory blood pressure values in healthy children and adolescents: a multicenter trial including 1141 subjects. J Pediatr. 1997;130:178-184. [PubMed: 9042117]

61. Siervo M, Lara J, Chowdhury S, Ashor A, Oggioni C, Mathers JC. Effects of the Dietary Approach to Stop Hypertension (DASH) diet on cardiovascular risk factors: a systematic review and metaanalysis. Br J Nutr. 2015;113:1-15. [PubMed: 25430608]

62. Asghari G, Yuzbashian E, Mirmiran P, Hooshmand F, Najafi R, Azizi F. Dietary Approaches to Sto $\mathrm{p}$ Hypertension (DASH) dietary pattern is associated with reduced incidence of metabolic syndrome in children and adolescents. J Pediatr. 2016;174:178-184.e1. [PubMed: 27156186]

63. Flynn JT, Kaelber DC, Baker-Smith CM, et al. Clinical practice guide-line for screening and Management of High Blood Pressure in children and adolescents. Pediatrics. 2017;140:e20171904-e20171975.

64. Wells T, Frame V, Soffer B, et al. A double-blind, placebo-controlled, dose-response study of the effectiveness and safety of enalapril for children with hypertension. J Clin Pharmacol. 2002;42:870-880. [PubMed: 12162469]

65. Soffer B, Zhang Z, Miller K, Vogt BA, Shahinfar S. A double-blind, placebo-controlled, doseresponse study of the effectiveness and safety of lisinopril for children with hypertension. Am J Hypertens. 2003;16:795-800. [PubMed: 14553956]

66. Marcovecchio ML, Chiesa ST, Bond S, et al. ACE inhibitors and statins in adolescents with type 1 diabetes. N Engl J Med. 2017;377: 1733-1745. [PubMed: 29091568]

67. Lv J, Perkovic V, Foote CV, Craig ME, Craig JC, Strippoli GFM. Antihypertensive agents for preventing diabetic kidney disease. Cochrane Database Syst Rev. 2012;12:CD004136.

68. Strippoli GFM, Craig M, Craig JC. Antihypertensive agents for preventing diabetic kidney disease. Cochrane Database Syst Rev. 2005; (4):CD004136.

69. Wu H-Y, Huang J-W, Lin H-J, et al. Comparative effectiveness of renin-angiotensin system blockers and other antihypertensive drugs in patients with diabetes: systematic review and bayesian network meta-analysis. BMJ. 2013;347:f6008-f6008. [PubMed: 24157497]

70. Strippoli GFM, Bonifati C, Craig M, Navaneethan SD, Craig JC. Angiotensin converting enzyme inhibitors and angiotensin II receptor antagonists for preventing the progression of diabetic kidney disease. Cochrane Database Syst Rev. 2006;9:CD006257.

71. Bangalore S, Fakheri R, Toklu B, Messerli FH. Diabetes mellitus as a compelling indication for use of renin angiotensin system blockers: systematic review and meta-analysis of randomized trials. BMJ. 2016;352:i438. [PubMed: 26868137] 
72. ACE Inhibitors in Diabetic Nephropathy Trialist Group. Should all patients with type 1 diabetes mellitus and microalbuminuria receive angiotensin-converting enzyme inhibitors? A meta-analysis of individual patient data. Ann Intern Med. 2001;134:370-379. [PubMed: 11242497]

73. Izzo JL, Weir MR. Angiotensin-converting enzyme inhibitors. J Clin Hypertens (Greenw ich). 2011;13:667-675.

74. Strippoli GFM. Effects of angiotensin converting enzyme inhibitors and angiotensin II receptor antagonists on mortality and renal outcomes in diabetic nephropathy: systematic review. BMJ. 2004; 329:828. [PubMed: 15459003]

75. Bullo M, Tschumi S, Bucher BS, Bianchetti MG, Simonetti GD. Pregnancy outcome following exposure to angiotensin-converting enzyme inhibitors or angiotensin receptor antagonists: a systematic review. Hypertension. 2012;60:444-450. [PubMed: 22753220]

76. Wong TY, Cheung CMG, Larsen M, Sharma S, Simó R. Diabetic retinopathy. Nat Rev Dis Primers. 2016;2:16012. [PubMed: 27159554]

77. Hietala K, Harjutsalo V, Forsblom C, Summanen P, Groop PH, on behalf of the FinnDiane Study Group. Age at onset and the risk of proliferative retinopathy in type 1 diabetes. Diabetes Care. 2010;33: 1315-1319. [PubMed: 20185730]

78. Stefánsson E. The case for biennial retinopathy screening in childr en and adolescents: response to Maguire et al. Diabetes Care. 2006;29: 178 author reply178-9. [PubMed: 16419356]

79. Maguire A, Chan A, Cusumano J, et al. The case for biennial retinopathy screening in children and adolescents. Diabetes Care. 2005;28: 509-513. [PubMed: 15735179]

80. Klein R, Klein BEK, Cruickshanks KJ. Assessing progress in retinopathy outcomes in type 1 diabetes: comparing findings from the Wisconsin diabetes registry study and the Wisconsin epidemiologic study of diabetic retinopathy. Diabetes Care. 2013;36:631-637. [PubMed: 23193204]

81. Liew G, Wong VW, Ho I-V. Mini review: changes in the incidence of and progression to proliferative and sight-threatening diabetic retinopathy over the last 30 years. Ophthalmic Epidemiol. 2017;24: 73-80. [PubMed: 28102748]

82. Liew G, Michaelides M, Bunce C. A comparison of the causes of blindness certifications in England and Wales in working age adults (16-64 years), 1999-2000 with 2009-2010. BMJ Open. 2014;4: e004015.

83. Scanlon PH, Stratton IM, Bachmann MO, Jones C, Leese GP, Four Nations Diabetic Retinopathy Screening Study Group. Risk of diabetic retinopathy at first screen in children at 12 and 13 years of age. Diabet Med. 2016;33:1655-1658. [PubMed: 27646856]

84. Huo B, Steffen AT, Swan K, Sikes K, Weinzimer SA, Tamborlane WV. Clinical outcomes and costeffectiveness of retinopathy screening in youth with type 1 diabetes. Diabetes Care. 2007;30:362363. [PubMed: 17259509]

85. Geloneck MM, Forbes BJ, Shaffer J, Ying G-S, Binenbaum G. Ocular complications in children with diabetes mellitus. Ophthalmology. 2015;122(12):2457-2464. [PubMed: 26341461]

86. Beauchamp G, Boyle CT, Tamborlane WV, et al. Treatable diabetic retinopathy is extremely rare among pediatric T1D exchange clinic registry participants. Diabetes Care. 2016;39:e218-e219. [PubMed: 27852686]

87. Wang SY, Andrews CA, Herman WH, Gardner TW, Stein JD. Incidence and risk factors for developing diabetic retinopathy among youths with type 1 or type 2 diabetes throughout the United States. Ophthalmology. 2017;124:424-430. [PubMed: 27914837]

88. Wang SY, Andrews CA, Gardner TW, Wood M, Singer K, Stein JD. Ophthalmic screening patterns among youths with diabetes enrolled in a large US Manag ed Care Network. JAMA Ophthalmol. 2017; 135(5):432-438. [PubMed: 28334336]

89. Early worsening of diabetic retinopathy in the Diabetes Control and Complications Trial. Arch Ophthalmol. 1998;116:874-886. [PubMed: 9682700]

90. Daneman D, Drash AL, Lobes LA, Becker DJ, Baker LM, Travis LB. Progressive retinopathy with improved control in diabetic dwarfism (Mauriac's syndrome). Diabetes Care. 1981;4:360-365. [PubMed: 7047112]

91. Axer-Siegel R, Hod M, Fink-Cohen S, et al. Diabetic retinopathy during pregnancy. Ophthalmology. 1996;103:1815-1819. [PubMed: 8942876] 
92. Best RM, Chakravarthy U. Diabetic retinopathy in pregnancy. Br J Ophthalmol. 1997;81:249-251. [PubMed: 9135391]

93. Bragge P, Gruen RL, Chau M, Forbes A, Taylor HR. Screening for presence or absence of diabetic retinopathy: a meta-analysis. Arch Ophthalmol. 2011;129:435-444. [PubMed: 21149748]

94. Klein R, Klein BE, Moss SE, Davis MD, DeMets DL. The Wisconsin epidemiologic study of diabetic retinopathy. II. Prevalence and risk of diabetic retinopathy when age at diagnosis is less than 30 years. Arch Ophthalmol. 1984;102:520-526. [PubMed: 6367724]

95. Mohamed Q, Gillies MC, Wong TY. Management of diabetic retinopathy: a systematic review. JAMA. 2007;298:902-916. [PubMed: 17712074]

96. The Diabetic Retinopathy Study Research Group. Photocoagulation treatment of proliferative diabetic retinopathy: clinical application of Diabetic Retinopathy Study (DRS) findings, DRS report number 8. Ophthalmology. 1981;88:583-600. [PubMed: 7196564]

97. Mitchell P, Foran S, Foran J. Guidelines for the Management of Diabetic Retinopathy. National Health and Medical Research Council of Australia, Commonwealth of Australia. 2008

98. Ferris F. Early photocoagulation in patients with either type I or type II diabetes. Trans Am Ophthalmol Soc. 1996;94:505-537. [PubMed: 8981711]

99. Sivaprasad S, Prevost AT, Vasconcelos JC, et al. Clinical efficacy of intravitreal aflibercept versus panretinal photocoagulation for best corrected visual acuity in patients with proliferative diabetic retinopathy at 52 weeks (CLARITY): a multicentre, single-blinded, randomised, controlled, phase 2b, non-inferiority trial. Lancet. 2017;389: 2193-2203. [PubMed: 28494920]

100. Writing Committee for the Diabetic Retinopathy Clinical Research Network, Gross JG, Glassman AR, et al. Panretinal photocoagulation vs Intravitreous Ranibizumab for proliferative diabetic retinopathy: a randomized clinical trial. JAMA. 2015;314:2137-2146. [PubMed: 26565927]

101. Diabetic Retinopathy Clinical Research Network, Wells JA, Glassman AR, et al. Aflibercept, bevacizumab, or ranibizumab for diabetic macular edema. N Engl J Med. 2015;372:1193-1203. [PubMed: 25692915]

102. Tan GS, Cheung N, Simó R, Cheung GCM, Wong TY. Diabetic macular oedema. Lancet Diabetes Endocrinol. 2017;5:143-155. [PubMed: 27496796]

103. Wilson ME, Levin AV, Trivedi RH, et al. Cataract associated with type-1 diabetes mellitus in the pediatric population. J AAPOS. 2007; 11:162-165. [PubMed: 17306995]

104. Zabeen B, Nahar J, Tayyeb S, Nahar N, Azad K, Donaghue K. Fibrocalculous pancreatic diabetes in Bangladeshi children and adolescents-a not so rare form of secondary diabetes. Int J Diabetes Dev Ctries. 2017;14:153.

105. Šimunović M, Paradžik M, Škrabić R, Unić I, Bućan K, Škrabić V. Cataract as early ocular complication in children and adolescents with type 1 diabetes mellitus. Int J Endocrinol. 2018;2018:6763586.

106. Jaiswal M, Lauer A, Martin CL, et al. Peripheral neuropathy in adolescents and young adults with type 1 and type 2 diabetes from the SEARCH for diabetes in youth follow-up cohort: a pilot study. Diabetes Care. 2013;36:3903-3908. [PubMed: 24144652]

107. Eppens MC. Prevalence of diabetes complications in adolescents with type 2 compared with type 1 diabetes. Diabetes Care. 2006;29: 1300-1306. [PubMed: 16732012]

108. Mohsin F, Craig ME, Cusumano J, et al. Discordant trends in microvascular complications in adolescents with type 1 diabetes from 1990 to 2002. Diabetes Care. 2005;28:1974-1980. [PubMed: 16043741]

109. Jaiswal M, Urbina EM, Wadwa RP, et al. Reduced heart rate variability among youth with type 1 diabetes: the SEARCH CVD study. Diabetes Care. 2013;36:157-162. [PubMed: 22961570]

110. Tang M, Donaghue KC, Cho YH, Craig ME. Autonomic neuropathy in young people with type 1 diabetes: a systematic review. Pediatr Diabetes. 2013;14:239-248. [PubMed: 23627912]

111. Hyllienmark L, Alstrand N, Jonsson B, Ludvigsson J, Cooray G, Wahlberg-Topp J. Early electrophysiological abnormalities and clinical neuropathy: a prospective study in patients with type 1 diabetes. Diabetes Care. 2013;36:3187-3194. [PubMed: 23723354]

112. Hajas G, Kissova V, Tirpakova A. A 10-yr follow-up study for the detection of peripheral neuropathy in young patients with type 1 diabetes. Pediatr Diabetes. 2016;17:632-641. [PubMed: 27028140] 
113. Russell JW, Zilliox LA. Diabetic neuropathies. Continuum (Minneap Minn). 2014;20:1226-1240. [PubMed: 25299279]

114. Tesfaye S, Chaturvedi N, Eaton SEM, et al. Vascular risk factors and diabetic neuropathy. N Engl J Med. 2005;352:341-350. [PubMed: 15673800]

115. Breiner A, Lovblom LE, Perkins BA, Bril V. Does the prevailing hypothesis that small-fiber dysfunction precedes large-fiber dysfunction apply to type 1 diabetic patients? Diabetes Care. 2014;37: 1418-1424. [PubMed: 24574353]

116. Tesfaye S, Boulton AJM, Dyck PJ, et al. Diabetic neuropathies: update on definitions, diagnostic criteria, estimation of severity, and treatments. Diabetes Care. 2010;33:2285-2293. [PubMed: 20876709]

117. Maser RE, Mitchell BD, Vinik AI, Freeman R. The association between cardiovascular autonomic neuropathy and mortality in individuals with diabetes: a meta-analysis. Diabetes Care. 2003;26: 1895-1901. [PubMed: 12766130]

118. Cho YH, Craig ME, Srinivasan S, et al. Heart rate variability in pubertal girls with type 1 diabetes: its relationship with glycaemic control, insulin resistance and hyperandrogenism. Clin Endocrinol. 2014;80: 818-824.

119. Thamotharampillai K. Decline in neurophysiological function after 7 years in an adolescent diabetic cohort and the role of aldose Reductase gene polymorphisms. Diabetes Care. 2006;29:2053-2057. [PubMed: 16936152]

120. da Silva TPB, Rolim LC, de Camargo Sallum Filho CF, Zimmermann LM, Malerbi F, Dib SA. Impaired awareness of hypoglycemia is associated with progressive loss of heart rate variability in patients with type 1 diabetes. Diabetol Metab Syndr. 2015;7:A63.

121. Tannus LRM, Drummond KRG, Clemente ELDS, da Matta Mde FB, Gomes MB, Brazilian Type 1 Diabetes Study Group (BrazDiab1SG). Predictors of cardiovascular autonomic neuropathy in patients with type 1 diabetes. Front Endocrinol (Lausanne). 2014;5:191. [PubMed: 25505446]

122. Choung RS, Locke GR, Schleck CD, Zinsmeister AR, Melton LJ, Talley NJ. Risk of gastroparesis in subjects with type 1 and 2 diabetes in the general population. Am J Gastroenterol. 2012;107:82-88. [PubMed: 22085818]

123. Braffett BH, Wessells H, Sarma AV. Urogenital autonomic dysfunction in diabetes. Curr Diab Rep. 2016;16:119. [PubMed: 27766580]

124. Laing SP, Swerdlow AJ, Slater SD, et al. Mortality from heart disease in a cohort of 23,000 patients with insulin-treated diabetes. Diabetologia. 2003;46:760-765. [PubMed: 12774166]

125. Hansson L, Zanchetti A, Caruthers SG. Effects of intensive blood-pressure lowering and low-dose aspirin in patients with hypertension: principal results of the hypertension optimal treatment (HOT) randomised trial. Lancet. 1998;351:1755-1762. [PubMed: 9635947]

126. Marcovecchio ML, Tossavainen PH, Acerini CL, et al. Maternal but not paternal association of ambulatory blood pressure with albumin excretion in young offspring with type 1 diabetes. Diabetes Care. 2010;33:366-371. [PubMed: 19918004]

127. Marcovecchio ML, Tossavainen PH, Owen K, et al. Clustering of cardio-metabolic risk factors in parents of adolescents with type 1 diabetes and microalbuminuria. Pediatr Diabetes. 2017;18: 947-954. [PubMed: 28271589]

128. Harrington J, Peña AS, Gent R, Hirte C, Couper J. Aortic intima media thickness is an early marker of atherosclerosis in children with type 1 diabetes mellitus. J Pediatr. 2010;156:237-241. [PubMed: 19853860]

129. Järvisalo MJ, Putto-Laurila A, Jartti L, et al. Carotid artery intima-media thickness in children with type 1 diabetes. Diabetes. 2002;51:493-498. [PubMed: 11812760]

130. Jarvisalo MJ. Endothelial dysfunction and increased arterial intima-media thickness in children with type 1 diabetes. Circulation. 2004;109:1750-1755. [PubMed: 15023875]

131. Larsen J, Brekke M, Sandvik L, Arnesen H, Hanssen KF, Dahl-Jørgensen K. Silent coronary atheromatosis in type 1 diabetic patients and its relation to long-term glycemic control. Diabetes. 2002;51:2637-2641. [PubMed: 12145181]

132. Nathan DM, Lachin J, Cleary P, et al. Intensive diabetes therapy and carotid intima-media thickness in type 1 diabetes mellitus. N Engl J Med. 2003;348:2294-2303. [PubMed: 12788993] 
133. Jenkins AJ, Lyons TJ, Zheng D, et al. Serum lipoproteins in the diabetes control and complications trial/epidemiology of diabetes intervention and complications cohort: associations with gender and glycemia. Diabetes Care. 2003;26:810-818. [PubMed: 12610042]

134. Idzior-Walus B, Mattock MB, Solnica B, Stevens L, Fuller JH, EURODIAB IDDM Complications Study Group. Factors associated with plasma lipids and lipoproteins in type 1 diabetes mellitus: the EURODIAB IDDM Complications Study. Diabet Med. 2001;18:786-796. [PubMed: 11678968]

135. Wadwa RP, Kinney GL, Maahs DM, et al. Awareness and treatment of dyslipidemia in young adults with type 1 diabetes. Diabetes Care. 2005;28:1051-1056. [PubMed: 15855566]

136. Maahs DM, Wadwa RP, Nadeau K, Eckel RH, Klingensmith GJ. Longitudinal lipid screening and use of lipid-lowering medications in pediatric type 1 diabetes. J Pediatr. 2007;150:146-150.e2. [PubMed: 17236891]

137. Guy J, Ogden L, Wadwa RP, et al. Lipid and lipoprotein profiles in youth with and without type 1 diabetes: the SEARCH for diabetes in youth case-control study. Diabetes Care. 2009;32:416420. [PubMed: 19092167]

138. Bjornstad P, Pyle L, Nguyen N, et al. Achieving International Society for Pediatric and Adolescent Diabetes and American Diabetes Association clinical guidelines offers cardiorenal protection for youth with type 1 diabetes. Pediatr Diabetes. 2015;16:22-30. [PubMed: 25604668]

139. Cholesterol Treatment Trialists' (CTT) Collaborators, Kearney PM, Blackwell L, et al. Efficacy of cholesterol-lowering therapy in 18,686 people with diabetes in 14 randomised trials of statins: a meta-analysis. Lancet. 2008;371:117-125. [PubMed: 18191683]

140. Collins R, Armitage J, Parish S, Sleigh P, Peto R, Heart Protection Study Collaborative Group. MRC/BHF Heart Protection Study of cholesterol-lowering with simvastatin in 5963 people with diabetes: a randomised placebo-controlled trial. Lancet. 2003;361:2005-2016. [PubMed: 12814710]

141. Wiegman A, Hutten BA, de Groot E, et al. Efficacy and safety of statin therapy in children with familial hypercholesterolemia: a randomized controlled trial. JAMA. 2004;292:331-337. [PubMed: 15265847]

142. Stein EA, Illingworth DR, Kwiterovich PO, et al. Efficacy and safety of lovastatin in adolescent males with heterozygous familial hypercholesterolemia: a randomized controlled trial. JAMA. 1999;281: 137-144. [PubMed: 9917116]

143. Langslet G, Breazna A, Drogari E. A 3-year study of atorvastatin in children and adolescents with heterozygous familial hypercholesterolemia. J Clin Lipidol. 2016;10:1153-1153. [PubMed: 27678432]

144. Haller MJ, Stein JM, Shuster JJ, et al. Pediatric Atorvastatin in Diabetes Trial (PADIT): a pilot study to determine the effect of atorvastatin on arterial stiffness and endothelial function in children with type 1 diabetes mellitus. J Pediatr Endocrinol Metab. 2009;22:65-68. [PubMed: 19344076]

145. de Ferranti SD, de Boer IH, Fonseca V, et al. Type 1 diabetes mellitus and cardiovascular disease: a scientific statement from the American Heart Association and American Diabetes Association. Diabetes Care. 2014;37:2843-2863. [PubMed: 25114297]

146. Doran B, Guo Y, Xu J, et al. Prognostic value of fasting versus non-fasting low-density lipoprotein cholesterol levels on long-term mortality: insight from the National Health and nutrition examination survey III (NHANES-III). Circulation. 2014;130:546-553. [PubMed: 25015340]

147. Nordestgaard BG, Langsted A, Mora S, et al. Fasting is not routinely required for determination of a lipid profile: clinical and laboratory implications including flagging at desirable concentration cutpoints-a joint consensus statement from the European Atherosclerosis Society and European Federation of Clinical Chemistry and Laboratory Medicine. Clin Chem. 2016;62:930-946. [PubMed: 27235445]

148. Fang ZY, Prins JB, Marwick TH. Diabetic cardiomyopathy: evidence, mechanisms, and therapeutic implications. Endocr Rev. 2004;25: 543-567. [PubMed: 15294881]

149. Raev DC. Left ventricular function and specific diabetic complications in other target organs in young insulin-dependent diabetics: an echocardiographic study. Heart Vessel. 1994;9:121-128. 
150. Fraser GE, Luke R, Thompson S, Smith H, Carter S, Sharpe N. Comparison of echocardiographic variables between type I diabetics and normal controls. Am J Cardiol. 1995;75:141-145. [PubMed: 7810489]

151. Regensteiner JG, Bauer TA, Reusch JEB, et al. Cardiac dysfunction during exercise in uncomplicated type 2 diabetes. Med Sci Sports Exerc. 2009;41:977-984. [PubMed: 19346991]

152. Lalande S, Hofman PL, Baldi JC. Effect of reduced total blood volume on left ventricular volumes and kinetics in type 2 diabetes. Acta Physiol (Oxf ). 2010;199:23-30. [PubMed: 20082608]

153. Lind M, Bounias I, Olsson M, Gudbjörnsdottir S, Svensson A-M, Rosengren A. Glycaemic control and incidence of heart failure in 20,985 patients with type 1 diabetes: an observational study. Lancet. 2011;378:140-146. [PubMed: 21705065]

154. Danielsen R. Factors contributing to left ventricular diastolic dysfunction in long-term type I diabetic subjects. Acta Med Scand. 1988; 224:249-256. [PubMed: 3239453]

155. Poirier P, Garneau C, Bogaty P, et al. Impact of left ventricular diastolic dysfunction on maximal treadmill performance in normotensive subjects with well-controlled type 2 diabetes mellitus. Am J Cardiol. 2000;85:473-477. [PubMed: 10728953]

156. Gusso S, Hofman P, Lalande S, Cutfield W, Robinson E, Baldi JC. Impaired stroke volume and aerobic capacity in female adolescents with type 1 and type 2 diabetes mellitus. Diabetologia. 2008;51: 1317-1320. [PubMed: 18446317]

157. Komatsu WR, Barros Neto TL, Chacra AR, Dib SA. Aerobic exercise capacity and pulmonary function in athletes with and without type 1 diabetes. Diabetes Care. 2010;33:2555-2557. [PubMed: 20807874]

158. Gusso S, Pinto TE, Baldi JC, Robinson E, Cutfield WS, Hofman PL. Diastolic function is reduced in adolescents with type 1 diabetes in response to exercise. Diabetes Care. 2012;35:2089-2094. [PubMed: 22773700]

159. Ross R. The pathogenesis of atherosclerosis: a perspective for the 1990s. Nature. 1993;362:801809. [PubMed: 8479518]

160. Meeking DR, Cummings MH, Thorne S, et al. Endothelial dysfunction in type 2 diabetic subjects with and without microalbuminuria. Diabet Med. 1999;16:841-847. [PubMed: 10547211]

161. Stehouwer CD, Fischer HR, van Kuijk AW, Polak BC, Donker AJ. Endothelial dysfunction precedes development of microalbuminuria in IDDM. Diabetes. 1995;44:561-564. [PubMed: 7729616]

162. Urbina EM, Wadwa RP, Davis C, et al. Prevalence of increased arterial stiffness in children with type 1 diabetes mellitus differs by measurement site and sex: the SEARCH for diabetes in youth study. J Pediatr. 2010;156:731-731. [PubMed: 20097360]

163. MacKenzie KE. Folate and vitamin B6 rapidly normalize endothelial dysfunction in children with type 1 diabetes mellitus. Pediatrics. 2006;118:242-253. [PubMed: 16818571]

164. Çiftel M, Ertuğ H, Parlak M, Akçurin G, Kardelen F. Investigation of endothelial dysfunction and arterial stiffness in children with type 1 diabetes mellitus and the association with diastolic dysfunction. Diab Vasc Dis Res. 2014;11:19-25. [PubMed: 24169808]

165. Babar GS, Zidan H, Widlansky ME, et al. Impaired endothelial function in preadolescent children with type 1 diabetes. Diabetes Care. 2011;34:681-685. [PubMed: 21289230]

166. Peña AS, Couper JJ, Harrington J, et al. Hypoglycemia, but not glucose variability, relates to vascular function in children with type 1 diabetes. Diabetes Technol Ther. 2012;14:457-462. [PubMed: 22313018]

167. Dye AS, Huang H, Bauer JA, Hoffman RP. Hyperglycemia increases muscle blood flow and alters endothelial function in adolescents with type 1 diabetes. Exp Diabetes Res. 2012;2012:170380170389. [PubMed: 22701470]

168. Peña AS, Maftei O, Dowling K, et al. Folate fortification and supplementation do not provide vascular health benefits in type 1 diabetes. J Pediatr. 2013;163:255-260. [PubMed: 23374677]

169. Constantino MI, Molyneaux L, Limacher-Gisler F, et al. Long-term complications and mortality in young-onset diabetes: type 2 diabetes is more hazardous and lethal than type 1 diabetes. Diabetes Care. 2013;36:3863-3869. [PubMed: 23846814] 
170. Wong J, Molyneaux L, Constantino M, Twigg SM, Yue DK. Timing is everything: age of onset influences long-term retinopathy risk in type 2 diabetes, independent of traditional risk factors. Diabetes Care. 2008;31:1985-1990. [PubMed: 18628565] 


\section{롤 \\ 골}

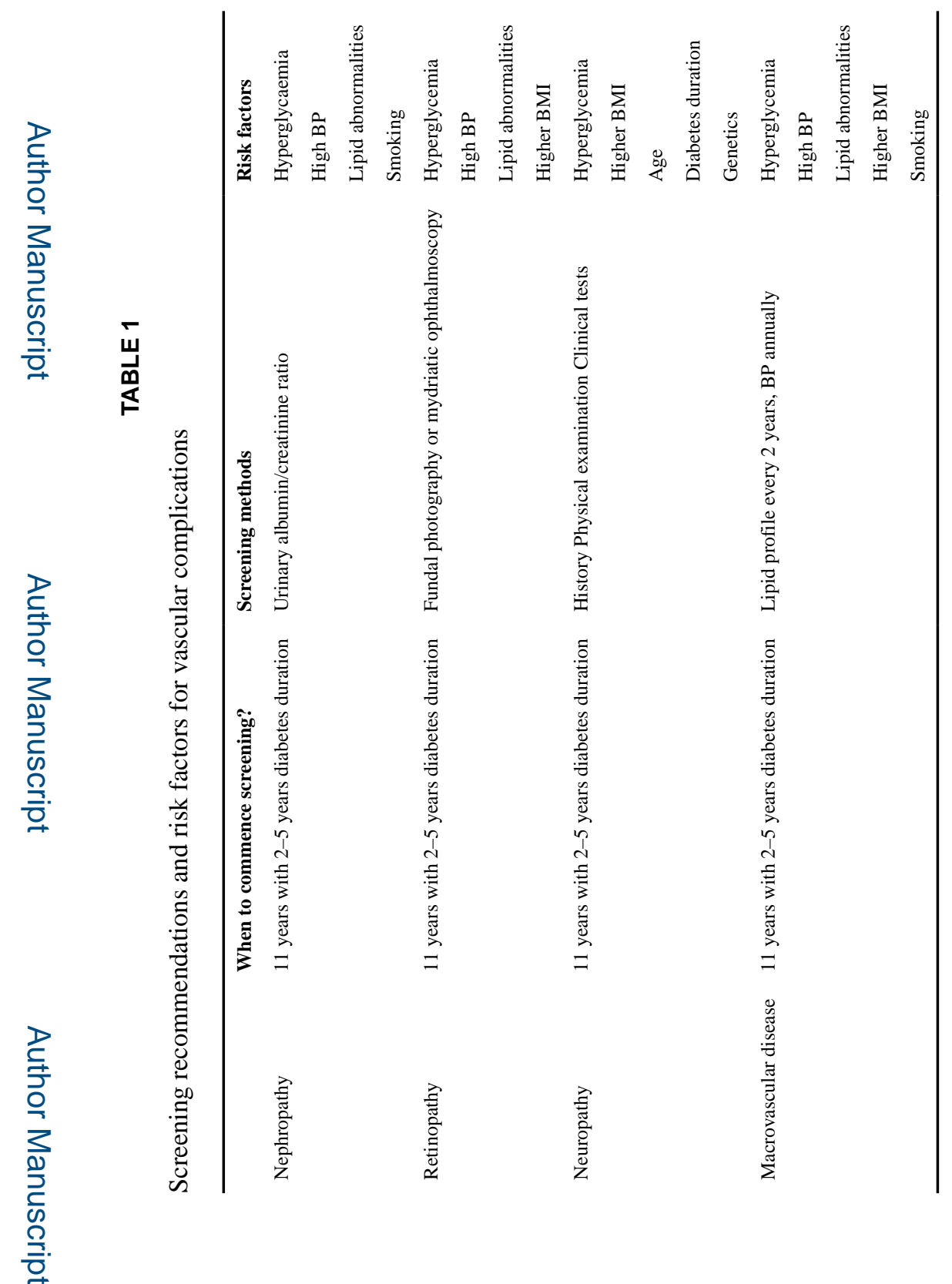

Pediatr Diabetes. Author manuscript; available in PMC 2021 November 01. 


\section{TABLE 2}

Recommended threshold values for different parameters for intervention and primary prevention of microvascular and CVD in children and adolescents with type 1 diabetes

\begin{tabular}{ll}
\hline Threshold value & Type of intervention \\
BP >90th percentile for age, gender and height & iLfestyle intervention: exercise, less screen time and diet \\
BP >90th percentile despite lifestyle intervention & ACE inhibitor or other BP lowering agent \\
& If microalbuminuria is present: ACE inhibitor or ARB \\
BP >95th percentile for age, gender and height & Lifestyle intervention and ACE inhibitor or other BP lowering agent \\
& If microalbuminuria is present: ACE inhibitor or ARB \\
LDL cholesterol $>2.6 \mathrm{mmol} / \mathrm{L}(100 \mathrm{mg} / \mathrm{dL})$ & Dietary and lifestyle intervention \\
LDL cholesterol $>3.4 \mathrm{mmol} / \mathrm{L}(130 \mathrm{mg} / \mathrm{dL})$ & Statins \\
\hline
\end{tabular}

